\section{Roots of dogma in biology}

SIR - I respond to the letter "Laymen in scientist's clothing?" (Nature 346, 505: 1990). My PhD research on the population genetics of host-plant adaptation of a major horticultural pest interfaces between empirical and fundamental studies and I have come to several conclusions.

Fundamental, theoretical studies tend to be inaccessible to the nonspecialist because of jargon, thus reducing their overall readability, and because of the tendency to use mathematics to explain arguments without attempting to summarize these arguments in a nonmathematical form. (While the importance of mathematics in biology must be recognized, it is for the biologist a tool to aid understanding and not an end in itself.)

Biologists tend to divide themselves into camps of empiricists or theorists, resulting in parallel but non-interacting development. This is mutually disadvantageous as well being bad scientific method (theory and experiment should go hand in hand - few biologists seem to be good at both).

My experience in the United Kingdom was that the teaching of biology at all levels places too much emphasis on learning by rote of theories and facts and pays too little attention to training people to think and work as scientists. I am grateful

\section{Investment in UK universities}

SIR-The report of Peter Aldhous (Nature 347, 216; 1990) about the settingup by the Japanese pharmaceutical company EISAI of a neurosciences research centre at University College, London, takes the opportunity to castigate British pharmaceutical companies for not investing in UK universitics.

I should like to redress the balance a little. About two-and-a-half years ago, I approached some British and overseas drug companies for support to set up a Centre for Applied Neuropsychobiology at the University of Oxford which would collaborate with the university departments of clinical pharmacology and psychiatry and the MRC Unit of Clinical Pharmacology. Several UK and overseas companies showed interest, and Beecham representatives quickly reached agreement in principle on the setting up of the Oxford University Beecham Centre of Applied Neuropsychology contiguous with the MRC unit and the university department of clinical pharmacology. Negotiations followed between the Unversity of Oxford, the Medical Research Council and Beccham Pharmaceuticals, which resulted in a legal agree- that all the science I learned at school was from the Nuffield syllabuses, which placed a strong emphasis on learning ideas from experimental observation and taught me to appreciate the fundamental principles underlying such observations. Such an approach necessarily led to a lesser accumulation of facts and figures, but I believe that it has greatly helped me in my development as a scientist. However, many universities regarded the Nuffield courses as containing too little academic content.

As a young researcher I try to use as many approaches as possible in tackling my research subject, believing that each (empirical and nonempirical) has its own merits and that each, if used properly, complements the other.

If we are to avoid the layman in scientist's clothing' syndrome in biology, I believe that we need to educate students in a way that trains them to be scientists. Such training should ensure that they are sufficiently literate to be capable of expressing their ideas effectively in everyday language

\section{Wageningen}

Agricultural University,

POB 8031 .

6700 EH Wageningen,

The Netherlands

ment covering all aspects of intellectual rights, royalties, publishing policy, staffing and progress review.

Refurbishment of vacant space in the Radcliffe Infirmary, Oxford, began in June 1989, and the laboratories were completed in October 1989. The centre is now up and running, research is under way publications have already appeared and the administration is working well. Senior scientists, graduate students and clinical scientists are working in the centre and collaborating with Beecham's own inhouse neuropharmacologists, molecular biologists and medicinal chemists.

There are twelve core scientific staff in the centre with agreed options on a further four. The contract for the centre is for ten years in the first instance, during which the investment is likely to be $£ 7.5$ million.

The contract was drawn up and signed before Beecham merged with Smith Kline and the new company, Smith Kline Beecham, has endorsed all the arrangements and funding.

This is a significant investment, and the initiative was wholly British.

D.G. GRAHAME-SMItH

MRC Clinical Pharmacology Unit,

University Department of Clinical

Pharmacology,

Radcliffe Infirmary.

Oxford OX2 6BE, UK
SIR-Infante and Huszagh' rightly complain about the now prevailing phenotype among researchers in biology; they describe it as poorly imaginative, lacking scepticism and creativity, but one that is productive in getting data published. They note that "there seem to be fewer and fewer people able to propose new schemes, or even to question the accepted ones".

But may it not be that there are as many such people now as previously, but that their naturally limited number is diluted nearly to infinity by the large crowd of 'kit-users' now working in biological research? This development was unfortunately brought about by the scientific community itself. By irresponsibly advertising biology as being able promptly to solve any urgent human problem - nutrition, health and so on - if only enough manpower (and money) were put into it, and by the obvious expansion-neurosis prevalent in any human enterprise, many who might have been better placed in other, perhaps more lucrative, jobs were attracted to it.

Sceptical and imaginative individuals do still exist among biologists. Recently, John Cairns and coworkers ${ }^{2}$ and Barry $\mathrm{Hall}^{3}$ set good examples for introducing uncertainty by questioning the accepted view concerning the origin of bacterial mutants (see also ref. 4). The present dogma rests on a famous experiment which proved that infection of a bacterial population by virulent phages does not induce mutations making bacteria phageresistant. Only those bacteria already resistant before encountering the phage could survive.

Yet with our present knowledge, we can ask how bacteria could ever have mutated if they were killed by the phages within minutes. What was overlooked when the outcome of the experiment became the basis of a universal dogma is (among other things) the possibility that the recruitment of mechanisms for directed mutagenesis might well need some time, which would be available to a bacterial population struggling for survival in a state of nutritional (and not immediately lethal) distress. Ideas of molecular mechanisms for induction of adaptively beneficial mutations may well be beyond the imagination of the "kit generation".

ULRIKE WINTERSBERGER

Department of Molecular Genetics,

Institute for Tumour Biology

and Cancer Research,

University of Vienna.

Borschkegasse 8a,

A-1090 Wien,

Austria

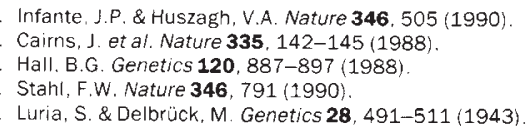

